\title{
High-Resolution Controller Data Performance Measures for Optimizing Diverging Diamond Interchanges and Outcome Assessment with Drone Video
}

\author{
Alexander M. Hainen \\ University of Alabama \\ Amanda L. Stevens \\ Indiana Department of Transportation \\ Christopher M. Day \\ Purdue University \\ Howell Li \\ Purdue University \\ Jamie Mackey \\ Utah Department of Transportation
}

Matt Luker

Utah Department of Transportation

Mark Taylor

Utah Department of Transportation

James R. Sturdevant

Indiana Department of Transportation

Darcy M. Bullock

Purdue University
PO Box 870205

Tuscaloosa, AL 35487-0205

(231) 883-2269

ahainen@ua.edu

8620 East $21^{\text {st }}$ St.

Indianapolis, IN 46219

(317) 796-2661

astevens@indot.in.gov

550 Stadium Mall Drive

West Lafayette, IN 47907-2051

(765) 494-9601

cmday@purdue.edu

550 Stadium Mall Drive

West Lafayette, IN 47907-2051

(765) 494-9601

howell-li@purdue.edu

2060 S 2760 W

Salt Lake City, UT 84104

(801) 887-3489

jamiemackey@utah.gov

2060 S $2760 \mathrm{~W}$

Salt Lake City, UT 84104

(801) 887-3627

mluker@utah.gov

2060 S 2760 W

Salt Lake City, UT 84104

(801) 887-3714

marktaylor@utah.gov

8620 East $21^{\text {st }}$ St.

Indianapolis, IN 46219

(317) 796-2661

jsturdevant@indot.in.gov

550 Stadium Mall Drive

West Lafayette, IN 47907

(765) 496-2226

darcy@purdue.edu

April 25, 2016 


\begin{abstract}
Diverging Diamond Interchanges (DDIs) are an emerging interchange configuration that eliminates the need for left-turn phases in conventional diamonds and may be less expensive to construct than some alternative geometries. This paper examines signal timing for DDIs. To date, DDI signal timing has typically used two-phase configuration reflecting the two competing movements at the cross-over points at each intersection of the DDI. This configuration inherently contains some inefficiency: i) there is potential for internal queuing under two-phase configuration, and ii) it is possible for the inflow demand to exceed outflow capacity of the interchange.

This paper uses high-resolution event data to develop performance measures to evaluate operations at a DDI in Salt Lake City, Utah. Alternatives to the existing signal timing within the two-phase configuration are modelled and tested with a field deployment. The field deployment demonstrated the ability to prioritize ramp or thru vehicles within the two-phase configuration. Additionally, a new three-phase configuration was developed and deployed to address the internal queuing that occurs with two-phase timing. Under this new configuration, the flows from one DDI intersection to the other are balanced and progression within the DDI is improved. By implementing the three-phase configuration, the percent of vehicles arriving on green at the heaviest internal movement within the DDI increased from 53\% to $92 \%$. To qualitatively illustrate these performance measures and improved DDI operation, a video from a tethered unmanned aerial vehicle (UAV) was prepared that demonstrates the vehicle arrival characteristics by overlaying vehicle detection and signal state graphics on the video.
\end{abstract}




\section{INTRODUCTION}

The Diverging Diamond Interchange (DDI) is an innovative interchange geometry whose use is increasing. Typically, DDI signal timing has consisted of a relatively simple two-phase configuration at each intersection. Most of the published literature on DDIs has focused on geometrics, capacity, and safety, with very little published on signal timings. This paper summarizes the DDI literature and describes the application of high-resolution controller data to develop performance measures to optimize DDI timing.

\section{BACKGROUND}

The diverging diamond interchange was developed by Chlewicki from 2000-2003 and was first deployed in the U.S. at I-44 and Kansas Expressway (SR 13) in Springfield, Missouri (1) (2). Bared et al. reported increased capacity at DDIs compared to regular diamond interchanges under various simulations mainly due to the elimination of the left-turn phase which reduces signal timing to a two-phase configuration (3). Several other papers used microsimulation-based evaluations (4) and all reported that for a majority of the cases that DDIs performed better than conventional diamond interchanges, single-point urban interchanges (5), and other alternative intersections often due to the two-phase signal operations (6). In recent work, the HCM delay formulas have been adapted to DDIs (7), simulation packages have been created (8), selection tools have been developed (9), split optimization software made available (10), and critical lane volume analysis tools implemented (11). Cycle length has been investigated (12) and timing the DDI with overlaps instead of a traditional two-phase configuration has been considered (13).

In summary, existing work has focused on simulation-based comparisons of the DDI to other operational types. This study reports on the application of high resolution traffic signal controller performance measures to assess DDI field operations and identify opportunities to improve signal timing. The evaluation is carried out during peak and off-peak periods for a DDI in Salt Lake City, Utah.

\section{PERFORMANCE MEASURE APPROACH}

One of the challenges of DDI timing is that under some demand scenarios there is an imbalance between upstream and downstream capacity. Given the relatively limited number of field deployments, there are opportunities to identify and establish performance measures that can be used for optimizing DDI timing efficiencies. This paper documents the following contributions

- First, performance measures are developed for the DDI. Graphical tools are applied to the case of the DDI to evaluate how the interchange is performing.

- The performance measure data is further applied to explore the optimization of traffic flows between the two intersections. By associating traffic signal states with vehicle detection times, it is possible to identify traffic origins (ramp or mainline) and optimize the total number of arrivals on green.

- To address the imbalance between upstream inflow demand and downstream intersection outflow capacity that is inherent in the two-phase configuration, a three-phase configuration which features a "hold-back" phase is proposed and tested in the field. The new configuration improves traffic flows within the DDI by balancing green times at each intersection so that periods of inflow are aligned with compatible greens, and eliminating stops and queuing in the middle of the interchange. 
- Lastly, video obtained from a tethered unmanned aerial vehicle (UAV) was prepared that demonstrates the vehicle arrival characteristics by overlaying vehicle detection and signal state graphics on the video.

\section{SITE CHARACTERISTICS}

The DDI at SR-201 and Bangerter Highway in Salt Lake City, Utah was the study interchange for this work. This interchange was formerly configured as a traditional diamond, but experienced substantial congestion during peak periods. Progression along the arterial (14) is a critical consideration at this location due to the high volume of truck traffic to/from the area north of the intersection (adjacent signal approximately 1,000 feet away), as well as the closely spaced signalized intersection to the south of the intersection (adjacent signal approximately 500 feet away). A DDI option was selected as the most cost effective upgrade to mitigate congestion. Figure 1 shows the lane configuration and phasing for the interchange that was re-constructed in 2011.

At the north intersection (WB ramp), there are two sources for SB traffic:

- $\quad$ External Southbound Thru (Overlap-E). Overlap-E is driven by Ø5 (phase 5) and Ø6.

- Westbound Left Movement (Overlap-H). Overlap-H from the ramp is driven by Ø8.

At the south intersection (EB ramp), there are two sources for NB traffic:

- External Northbound Thru (Overlap-A). Overlap-A is driven by Ø1 and Ø2.

- Eastbound Left Movement (Overlap-D). Overlap-D from the ramp is driven by Ø4.

Each ramp intersection includes two movements that provide separate inflows to the other intersection. In Figure 1, the black arrows (OL-E and OL-A) are the movements from the external thru movements along Bangerter Highway, and the gray arrows (OL-H and OL-D) are the movements carrying traffic off the ramps. All ramp movements are signalized and turning left on red is not permitted.

A 60-second cycle length was used with a 5-second offset between the rings. Ring 1 handles the south intersection and Ring 2 handles the north intersection. The even-numbered phases $(2,4,6,8)$ each have 23 -second splits. The odd-numbered phases $(1,3,5,7)$ each have 7 second splits. The sole purpose of the odd-numbered phases is to provide additional clearance time to allow the vehicles in the cross-over area to clear the off-ramp conflict points before allowing ramp traffic to proceed. Backup prevention rules were programmed in the controller to ensure that these clearance phases are always served. In some controllers, the same behavior could possibly be achieved without using separate phases by using leading overlaps with red time.

Although the ramp and thru movements are controlled by overlaps at this location, the existing timing is effectively the same as "two-phase” operation, since each intersection effectively alternates between two states (northbound or southbound at each intersection). The north intersection alternates between Overlaps $\mathrm{G}$ and $\mathrm{E}$ while the south intersection alternates between Overlaps A and C. Changing the number of "phases" is considered later in this paper. The locations of the advance detectors are shown in Figure 1. Radar detection was used. The posted speed limit on the bridge is $40 \mathrm{MPH}$.

\section{PERFORMANCE MEASURES}

In previous studies, Indiana has leveraged high-resolution event-based data (15) to develop performance measures for engineers to better understand arrival characteristics and other 
operational characteristics at intersections (16). The two common performance measures used are the Purdue Coordination Diagram (PCD) and the flow profile diagram.

\section{Purdue Coordination Diagram}

The PCD (17) is a graphical tool for visualizing progression between intersections. Each vehicle arrival time at the stop bar is plotted by the time of day along the horizontal axis and by time in cycle along the vertical axis. Moving from the $\mathrm{x}$-axis upward, the beginning of the cycle is the beginning of red; the next event is the start of green (green line), and the final event is the end of green (red line). Vehicle arrivals represented by dots below the green line represent arrivals on red, while dots above the green line represent arrivals on green. The greater the proportion of dots above the green line, the higher the percent of arrivals on green and the better the progression of vehicles. Figure $2 \mathrm{a}$ and Figure $2 \mathrm{~b}$ are further enhanced by coding the arrivals according to their originating phase.

Figure 2a is the PCD for the northbound movement at the north intersection. The black dots (northbound thru vehicles) are located in a dense band immediately following the start of green. This suggests that at the start of green, the vehicles in this platoon arrive shortly after the start of green, and experience favorable progression. The gray dots (ramp vehicles) appear late in the green, and about half of the platoon is cut off by the end of green. Notice how the platoon carries over into the next cycle (gray dots near the x-axis). This suggests that these vehicles queue in the interior of the interchange. During the peak periods, growing queues in the interior of the interchange can be problematic since those queues must be cleared to enable additional vehicles to proceed. It is therefore preferable to avoid internal queuing as much as possible. The vehicles in the green band can be counted and a percent on green (POG) of 64.0\% is measured.

The PCD for the southbound movement at the south intersection is shown in Figure $2 \mathrm{~b}$. The black dots (southbound thru vehicles) are located in a band immediately following the start of green. This movement is working well, and the entire platoon arrives on green. The gray dots (ramp vehicles) mostly occur after the start of red, and before the beginning of green. Since all of these vehicles arrive on red, this platoon is clearly not progressing and experiences long queues. The total interior southbound thru movement has a measured POG of 53.5\%.

\section{Flow Profile Diagrams}

The flow profile diagrams (Figure 2c and Figure 2d) capture the same phenomena observed in the PCDs, but present the information as distributions over the cycle length. This illustrates conditions for an average cycle during the related time period. This plot shows several pieces of information for each 1-second bin of the cycle length. The green shading indicates the probability that the signal is green at that time. The vertical bars show the number of vehicles arriving during a given time in the cycle. The black bars represent thru vehicles while the gray bars represent ramp vehicles.

In Figure 2c, the black bars (northbound thru vehicles) overlap very well with the interior northbound thru green portion of the cycle. This is consistent with the PCD (Figure 2a) and these vehicles are achieving a measured POG of 78.8\%. However, most of the gray bars (ramp vehicles) do not overlap with the green, indicating arrivals on red. The measured POG is $39.8 \%$. As seen in the PCD, the first part of the platoon arrives during green, but is clipped by the end of green that occurs around 5 seconds into the cycle (i.e., the probability of green drops to zero).

The interior southbound movement (Figure 2d) performs similarly, but exhibits even greater disparity in quality of progression of the thru and ramp vehicles. Figure $2 \mathrm{~d}$ shows that the platoon of thru vehicles arrives almost entirely during green. The measured POG is 95.8\%. In 
contrast, the ramp vehicles arrive almost entirely during red, and the measured POG is only 6.1\%. It was desirable to increase the ramp movement progression to keep the interstate clear.

\section{OFFSET ADJUSTMENT}

The offset between the two intersections largely determines the characteristics of traffic flow within the interchange. In this situation, since each intersection is controlled by one ring in the same controller, the relevant controller setting that controls the amount of time between events occurring in ring 1 and ring 2 is the "ring offset" or "ring displacement".

In the existing timings, the splits at each intersection evenly divide the cycle between two competing sets of movements (Figure 1). For example, at the north intersection, Overlap $G$ is served during $50 \%$ of the cycle, while Overlap E is green the other $50 \%$ of the cycle. Overlaps $\mathrm{F}$ and $\mathrm{H}$ are slightly smaller (38\%), since they exclude the clearance phases. Note that only $50 \%$ of the cycle time is available for the internal thru movements, yet there are movements entering the internal movements during both phases of the upstream DDI signal. From this, one would expect the overall outgoing POG to be no better than 50\%. Note that AOG does not matter for left turns to the on-ramp as long as queues do not block access. This is clearly the case for the south intersection (Figure 2b, Figure 2d). The north intersection is able to perform just slightly better in terms of the overall POG (Figure 2a, Figure 2c) because the eastbound left from the ramp has a significantly smaller volume than the northbound thru. Without the ability to adjust splits, the other two changes that can be made are the cycle length and the offset. The cycle length is determined by the adjacent corridor, so the offset is the easiest parameter to consider changing.

It has been demonstrated previously that measured vehicle arrival profiles can be used to predict conditions for proposed changes to offsets (17). The vehicle arrival times are adjusted by the proposed amount of change in the offset to construct a predictive PCD. Using measured profiles rather than modeled arrivals or bandwidth enables the offset to be optimized for the actual arrival patterns, and preserves operational nuances such as the relatively light volume, speeds, driver behavior, etc. of the eastbound left turn at the south intersection.

Figure 3 shows a series of PCDs that illustrate modelled conditions for the southbound movement at the south intersection under different offset adjustments ranging across the entire cycle length. Starting with the observed POG of 53.5\% (Figure 3a), conditions under other potential offsets are shown in Figure 3b-f using 10-second increments. For example, if the existing offset of 5 seconds (Figure 1) was increased by 10 seconds $(\Delta=+10)$ to an offset of 15 seconds, then Ring 2 in Figure 1 would slide to the right by 10 seconds; vehicle detections from OL-E and OL-H would arrive 10 seconds later relative to OL-C green at the south intersection. The POG is recalculated and estimated to be $46.3 \%$ (Figure $3 \mathrm{~b}$ ). Since the POG decreased, this change would not be recommended. While Figure 3 showed six particular offset adjustments, the POG and the total number of arrivals on green (AOG) can be easily calculated for any offset.

An exhaustive offset sweep is shown in Figure 4. Figure 4a and Figure 4b respectively show the northbound and southbound POG for each offset adjustment while Figure 4c and Figure $4 d$ respectively show the northbound and southbound AOG. Figure 4e shows the POG for both intersections together. In Figure 4a and Figure 4c, there is clearly one part of the cycle where the POG and AOG is highest. Because the north intersection has more vehicles originating from the upstream thru movement than the upstream ramp movement, better progression is achieved by aligning the thru vehicles with the green. However, Figure $4 \mathrm{~b}$ and Figure $4 \mathrm{~d}$ show conditions at the south intersection where the upstream inflows are more evenly balanced. In Figure 4b, the thick black line is almost completely flat, with a POG of about 50\% no matter which offset is selected. 


\section{Reprioritizing Movements}

Under existing conditions, vehicle platoons from the upstream thru movements were prioritized and mostly arrived during green (black symbols in Figure 2b) while vehicle platoons from the ramp movements (gray symbols in Figure 2a and b) mostly arrived during red. In Figure 4e, the maximum POG occurs at $\Delta=0$. This indicates the current offset is optimal. Figure $4 \mathrm{~b}$ shows that the SB thru movement POG (thin black line) is over $90 \%$ at $\Delta=0$, while the southbound ramp movement POG (gray line) is very poor, at less than 10\%. An adjustment of $\Delta=+30$ would invert this relationship with ramp vehicles having excellent POG and thru vehicles having poor POG. Also, note that the offset adjustment affects progression at both intersections. It is not possible, based on the optimization results for this interchange, to progress ramp vehicles at one intersection and thru vehicles at the other. This illustrates a fundamental trade-off problem in two-phase DDIs and prompts careful selection based on traffic demand patterns as to where DDIs are implemented.

To validate the prediction and to demonstrate how ramp or thru vehicles can be reprioritized with offset adjustment, an adjustment of 30 seconds was made in the field. Figure 5a and Figure 5b show the platoon arrival characteristics under the existing timings on December 17, 2013. Figure 5c and Figure 5d show the predicted conditions under the proposed offset adjustment of 30 seconds. At the southbound approach at the south intersection, the ramp vehicles (gray bars) go from arriving mostly in red (Figure 5b) to mostly in green (Figure 5d), while the thru vehicles (black bars) move from green to red. The offset change was implemented for the midday timing plan (9:00-14:00) on December 18, 2013 and the observed platoon arrival characteristics are shown in Figure 5e and Figure 5f. For the southbound movement, Figure $5 f$ closely matches the predicted performance in Figure 5d. The northbound movement was also predicted reasonably well (compare Figure 5e with Figure 5c). In this case, queues extending into the detection area likely affected the measured profiles for vehicles arriving later in the red in Figure 5e.

\section{Cumulative Distributions}

To analytically compare these arrival characteristics, cumulative distributions of the arrival profiles and green band service are shown in Figure 6. The arrival distributions for the SB movement shown in Figure 6a matched the predicted results very closely. Also, the predicted and actual green time matched nearly perfectly (Figure 6b), which is not unexpected since the actuated portion was only $10 \%$ of the cycle.

The predictions for the northbound approach (Figure 6c and Figure 6d) also worked reasonably well, with the cumulative profiles of the predicted and actual lining up relatively closely. Scheduling the thru vehicles to arrive during red caused the formation of long queues in the interior of the interchange, which affected vehicle detection and contributed to the disparity. However, these results are as expected. In Figure 4a and Figure 4c, an offset adjustment of $\Delta=30$ was predicted to degrade the overall performance of the northbound approach for this reprioritization experiment.

\section{THREE-PHASE OPERATIONS}

As mentioned earlier, the signals are operating as two phase signals, because the geometry of the design allows the left-turning movements to operate as free movements without requiring separate signal phases. The previous analysis shows that this produces two inflows to the downstream intersection: one from the upstream thru movement and the other from the upstream ramp movement. As shown in Figure 4 and Figure 5, only modest improvements in POG can be achieved by adjusting offsets, and in practical terms it is only possible to choose between the ramp or thru movements for prioritization. 
Given the trade-off problem between the ramp and thru vehicles under this "two-phase" operation, an alternative configuration was devised with the objectives of progressing both ramp and thru traffic and to minimize internal stops and internal queuing, a problem which occurred at this interchange. This alternative is a "three-phase" configuration that incorporates a hold-back phase during which no vehicles are fed into the internal approach. At each intersection of the interchange, there are now three "phases" in the cycle rather than two:

- "Two-phase” operation. Each internal approach alternates between the thru movement inflow and the ramp movement inflow.

- "Three-phase” operation. Each intersection cycles between the thru movement inflow, the hold-back "phase" (no inflow), and the ramp movement inflow.

One of the reasons why the DDI is appealing is that its simple two-phase timing configuration is constantly serving a major movement (thru or ramp) - i.e., there are no left turn phases. However, as demonstrated by the performance measures, with heavy volumes only half of those vehicles can progress through the other intersection of the DDI. The underlying constraint that must be evaluated is to verify there is enough capacity at the downstream intersection to handle the inflows from the upstream intersection.

Referring to Figure 7, the capacity is:

$$
c=n * s * \frac{g}{C}
$$

where $c$ is the capacity, $n$ is the number of lanes, $s$ is the saturation flow rate, $g$ is the effective green time, and $C$ is the cycle length.

The volume-to-capacity ratio (v/c) is defined as:

$$
\frac{v}{c}=\frac{Q_{d}}{n_{d} * s * \frac{g_{d}}{C}}
$$

Where $Q_{d}$ is the demand flow rate at the downstream signal, and $g_{d}$ is the green time at the downstream signal. Assuming saturation $(v / c=1.0)$,

$$
Q_{d}=n_{d} * s * \frac{g_{d}}{C}
$$

The downstream outflow must be equal to or greater than the upstream inflow:

$$
Q_{d} \geq Q_{a}+Q_{r}
$$

Eq. 4

Where $Q_{d}$ is the downstream flow rate, $Q_{a}$ is the upstream thru inflow, and $Q_{r}$ is the upstream ramp inflow. $Q_{h}$ (the volume getting on the freeway) is neglected during this PM peak period example when $Q_{d}>>Q_{h}$. 
From Eq. 4, and assuming all flow rates operating at v/c = 1.0 (Eq. 3),

$$
n_{d} * s * \frac{g_{d}}{C} \geq n_{a} * s * \frac{g_{a}}{C}+n_{r} * s * \frac{g_{r}}{C}
$$

Assuming that the saturation flow rate is the same for each movement, and given that the cycle length is the same, this simplifies to

$$
n_{d} * g_{d} \geq n_{a} * g_{a}+n_{r} * g_{r} \quad \text { Eq. } 6
$$

For the test site, $n_{d}=n_{a}=n_{r}(=3)$. Thus,

$$
\begin{array}{ll}
g_{d} \geq g_{a}+g_{r} & \text { Eq. } 7
\end{array}
$$

The downstream green must be greater than or equal to the upstream ramp and thru greens in order to avoid an imbalance during $\mathrm{v} / \mathrm{c}=1$. This is not the case under two-phase timing which causes congestion within the DDI when the two inflows (ramp and thru) collectively exceed the capacity of the downstream intersection.

Figure 8a conceptually illustrates the flows through the DDI, while Figure 8c shows the existing signal timing. Under "two-phase" operation, the thru movement split at the north intersection is $50 \%$ of the cycle (black arrow, Ø5 and Ø6) while the ramp split is $38 \%$ of the cycle (gray arrow, Ø8). Thus, for $88 \%$ of the cycle, there is an inflow feeding into the south intersection. However, the south intersection split is only $50 \%$ of the cycle (blue arrow, Ø3 and Ø4). In summary, the inflow exceeds the outflow.

The alternative "three-phase" scheme is illustrated in Figure 8b, with the new signal timing in Figure 8d. By introducing a hold-back phase into the sequence, the splits for the thru movement (black arrow, Ø5 and Ø6) and ramp movement (gray arrow, Ø8) at the north intersection are both reduced to 33\% of the cycle, while the thru movement at the south intersection (blue arrow, Ø3 and $\varnothing 4$ ) is increased to $66 \%$ of the cycle. Under this configuration, the inflow and outflow are balanced across the interchange, which was expected to eliminate or minimize internal queuing. As shown in Figure 8d, the hold-back phase is implemented and the downstream green times are increased by adjusting the splits of phases 7 and 3. The cycle length is also increased from 60 seconds to 90 seconds to accommodate the new sequence. In implementing this change, it was also necessary to adjust the neighboring signals to achieve progression along Bangerter Highway.

\section{Field Implementation Results}

The "three-phase" configuration was implemented in the field and the results were very positive overall. Under "two-phase" operation (Figure 8e), the POG is 52.6\%. The ramp vehicles (gray dots) mostly arrive on green while the thru vehicles (black dots) mostly arrive on red. Under "threephase" operation (Figure 8f), traffic flows within the DDI are considerably improved. Both the ramp and thru vehicles are mostly served during green, with an overall POG of 92.0\%. Only a few vehicles from the external thru movement (including indiscernible vehicles turning on to the interstate) are cut off at the end of green, a situation which might be improved by optimizing the offset. Nevertheless, the performance is better than all of the thru vehicles arriving in red under "two-phase" operation. 
Still pictures and links to video from video taken with a tethered UAV during the field study are included in Figure 9 (18).

- "Two-phase" operation. Figure 9a shows the southbound thru movement at the south intersection, looking northward to the north intersection. This image is taken at the start of green. There is a substantial queue of vehicles from the external southbound thru movement (callout “i”). Upstream, the westbound ramp movement (callout "ii”) is green, but the vehicles cannot immediately proceed because of the extent of the queuing. This situation corresponds to the PCD in Figure 8e.

- "Three-phase" operation. Figure 9b and Figure 9c show video frames from tethered UAV on a day when three-phase operation featuring a hold-back phase was used (scannable QR codes embedded and the video URL in the figure caption are included for access). Figure $9 \mathrm{~b}$ shows conditions at the end of green at the south intersection, which is also the beginning of the hold-back phase. There were only two cars clipped by the start of red (callout "iii"), and the rest of the interior is clear (callout "iv"), allowing the westbound ramp movement (callout "v") to proceed through the north intersection. Figure 9c shows conditions just after the start of southbound green at the south intersection. The stopped vehicles have moved past the stop bar (callout "vi"), and the platoon from the westbound ramp (callout "vii") have proceeded across the bridge without encountering queues, experiencing a superior arrival on green. Figure 9d shows the tethered GPS-assisted UAV operating at an altitude less than 100' according to on-board telemetry. 


\section{CONCLUSIONS}

DDIs are relatively rare and as agencies bring them on line it is important to have automated performance measures for characterizing their performance as well as identifying opportunities for agencies to improve timings. This paper has extended PCD and flow profile techniques to characterize DDI performance and identify operational improvements using high resolution controller data from the DDI at SR-201 and Bangerter Highway in Salt Lake City, Utah and provides the following contributions:

- Performance measures were developed for the DDI. The Purdue Coordination Diagram (PCD) and flow profile diagrams were used to characterize the performance of the interchange. These metrics can be used for any timing plan by time of day, and enable observation of conditions on weekends and at other times when the engineer cannot directly observe the interchange.

- An offset adjustment procedure was developed and validated by field deployment. A comprehensive sweep of the offset range was conducted, and movements can be prioritized by the engineer. However, under conventional two-phase DDI operations, the arrival on green performance hovers around 50\% for balanced external demands.

- A three-phase configuration featuring a hold-back phase was developed and implemented. This configuration balances the supply of downstream green time with the upstream demand and increased the POG from 53\% to 92\% for the heaviest internal movement. The three-phase operation is a tool for practitioners to obtain improved progression for a corridor and alleviate gridlock conditions during peak periods.

- One of the appealing aspects of DDIs is the two-phase timing structure which is intended to eliminate left-turn phases. However, the increased capacity of an upstream intersection cannot exceed the capacity of the downstream intersection. Under a three-phase configuration, the upstream intersection is no longer constantly serving vehicles from the ramp or thru inflows, internal queuing is largely eliminated from within the interchange, and the quality of progression is considerably improved.

- Three-phase operation is most appropriate to consider with heavy thru movement volumes, especially when both the ramp and external thru movements are heavy. External queuing outside of the DDI and throughput through the DDI were not quantitatively measured.

- The use of tethered UAVs is useful for watching interchange operations. The sight obstruction from the vertical curvature and wide bridge span makes it hard to observe both intersections at once. Combining the video with high-resolution event-based data gives detailed documentation of operations.

\section{ACKNOWLEDGEMENT}

This work was supported in part by the Joint Transportation Research Program and Pooled Fund Study (TPF-5(258)) led by the Indiana Department of Transportation (INDOT) and supported by the state transportation agencies of California, Georgia, Kansas, Minnesota, Mississippi, New Hampshire, Texas, Utah, Wisconsin, and Pennsylvania, the Federal Highway Administration Arterial Management Program, and the Chicago Department of Transportation. The contents of this paper reflect the views of the authors, who are responsible for the facts and the accuracy of the data presented herein, and do not necessarily reflect the official views or policies of the sponsoring organizations. These contents do not constitute a standard, specification, or regulation. 


\section{WORKS CITED}

1. Chlewicki G. New Interchange and Intersection Designs: The Synchronizsed Split-Phasing Intersection and the Diverging Diamond Interchange. In 2nd Urban Street Symposium; 2003 July; Anaheim. p. 1-16.

2. Clewicki G. Should the Diverging Diamond Interchange Always Be Considered a Diamond Interchange Form? Transportation Research Record. 2011: p. 88-96.

3. Bared JG, Edara PK, Jagannathan R. Design and Operational Performance of Double Crossover Intersection and Diverging Diamond Interchange. Transportation Research Record. 2005; 1912(31-38): p. 1-18.

4. Sharma S, Chatterjee I. Performance Evaluation of the Diverging Diamond Interchange In Comparison With the Conventional Diamond Interchange. In Transportation Scholars Conference; 2007; Ames. p. 1-13.

5. Afshar AM, Bared JG, Wolf S, Edara PK. Traffic Operational Comparison of Single-Point and Diverging Diamond Interchanges. In Transportation Research Board; 2009; Washington, D.C. p. $1-21$.

6. Hughes W, Jagannathan R, Sengupta D, Hummer J. Alternative Intersections/Interchanges: Informational Report (AIIR). Report. Washington, D.C.: U.S. Department of Transportation, Federal Highway Administration; 2010. Report No.: FHWA-HRT-09-060.

7. Xu H, Liu H, Tian Z, Zhang W. Control Delay Calculation at Diverging Diamond Interchanges. Transportation Research Record. 2011: p. 121-131.

8. Anderson M, Schroer B, Moeller D. Analyzing the Diverging Diamond Interchange Using Discrete Event Simulation. Modelling and Simulation in Engineering. 2012; Article ID 639865(doi:10.1155/2012/639865).

9. Yang X, Lu Y, Chang GL. An Integrated Computer System for Analysis, Selection, and Evaluation of Unconventional Intersections. Report. College Park: Maryland Department of Transportation, State Highway Administration; 2011. Report No.: SP909B4H.

10. Yang X, Chang GL, Rahwanji S. Development of a Signal Optimization Model for Diverging Diamond Interchange. Journal of Transportation Engineering. 2014; 140(0733947X/04014010(9)).

11. Maji A, Mishra S, Jha MK. Critical Lane Volume (CLV)-based Capacity and Level of Service Analyses for Diverging Diamond Interchanges. In Transportation Research Record; 2013; Washington D.C. p. 1-16.

12. Hu P, Tian ZZ, Xu H, Wu X. Effect of Cycle Length of a New Traffic Signal Timing on Diverging Diamond Interchange. In Transportation Research Board; 2014; Washington D.C. p. 1-16.

13. Hu P, Tian ZZ, Xu H, Andalibian R. An Advanced Signal Phasing Scheme for Divergin Diamond Interchanged. In Transportation Research Board; 2014; Washington, D.C. p. 1-15. 
14. Chaudhary NA, Chu CL. Guidelines for Timing and Coordinating Diamond Interchanges with Adjacent Traffic Signals. College Station. 2000.

15. Smaglik EJ, Sharma A, Bullock DM, Sturdevant JR, Duncan G. Event-based data collection for generating actuated controller performance measures. Transportation Research Record. 2007; 2035(10.3141/2035-11).

16. Day CM, Bullock DM, Li H, Remias SM, Hainen AM, Freije RS, et al. Performance Measures for Traffic Signal Systems: An Outcome-Oriented Approach. 1057031288284315232th ed. West Lafayette: Purdue University Press; 2014.

17. Day CM, Haseman R, Premachandra H, Brennan Jr. TM, Wasson JS, Sturdevant JR, et al. Methodologies for Visualizing High-Resolution Event Data and Measuring Travel Time. Transportation Research Record. 2011 February; 2192(10.3141/2192-04).

18. Hainen AM, Stevens AL, Li H, Bullock DM. Three-Phase Operations at a Diverging Diamond Interchange Using an Unmanned Aerial Vehicle (UAV) Camera [Video].; 2014. Available from: http://dx.doi.org/10.4231/R7C24TC4. 


\section{LIST OF FIGURES}

Figure 1 Lane Configuration and phase mapping at SR-201@Bangerter Highway in Salt Lake

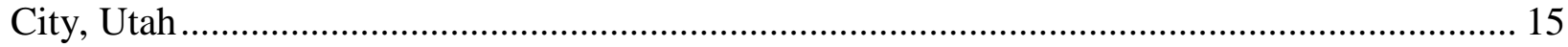

Figure 2 Performance measures for base 2-phase conditions on 12/17/2013........................... 16

Figure 3 PCDs showing the offset sweep effect on platoon arrivals (OL-C) ............................ 17

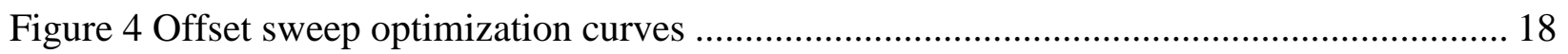

Figure 5 Before, Predicted, and After flow profile diagrams of the offset change..................... 19

Figure 6 Model performance evaluation............................................................................. 20

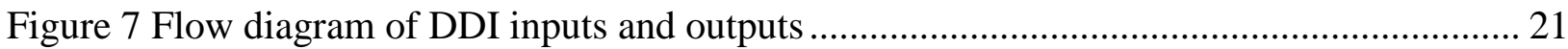

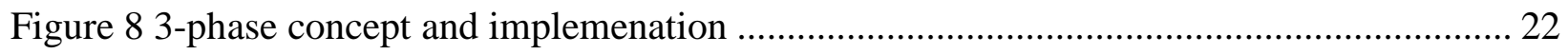

Figure 9 Visual assessment with video documentation of the 3-phase implementation

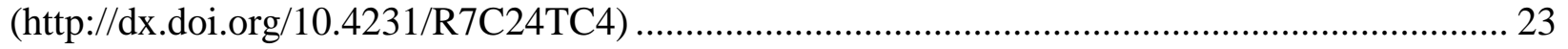




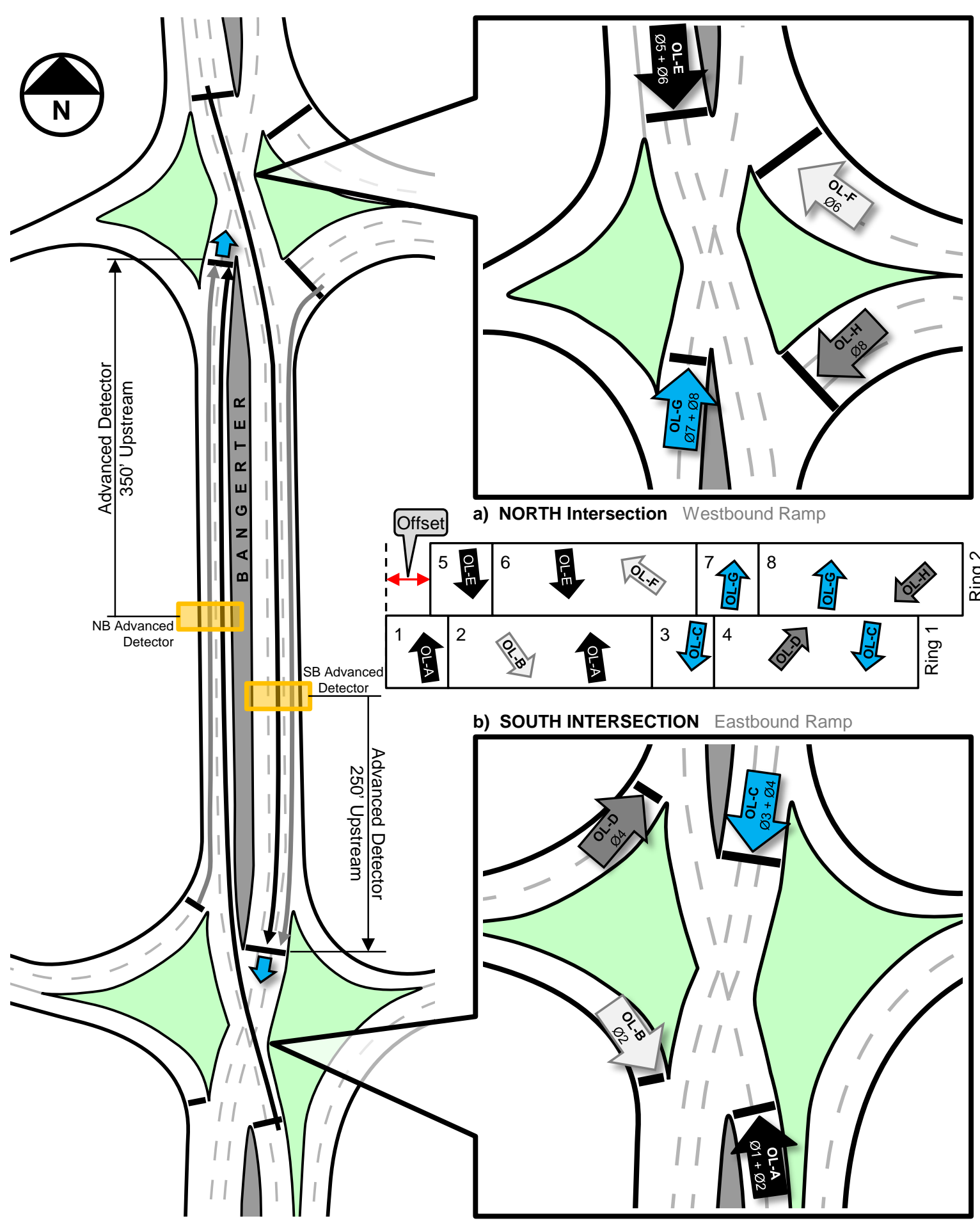

Figure 1 Lane Configuration and phase mapping at SR-201@Bangerter Highway in Salt Lake City, Utah 


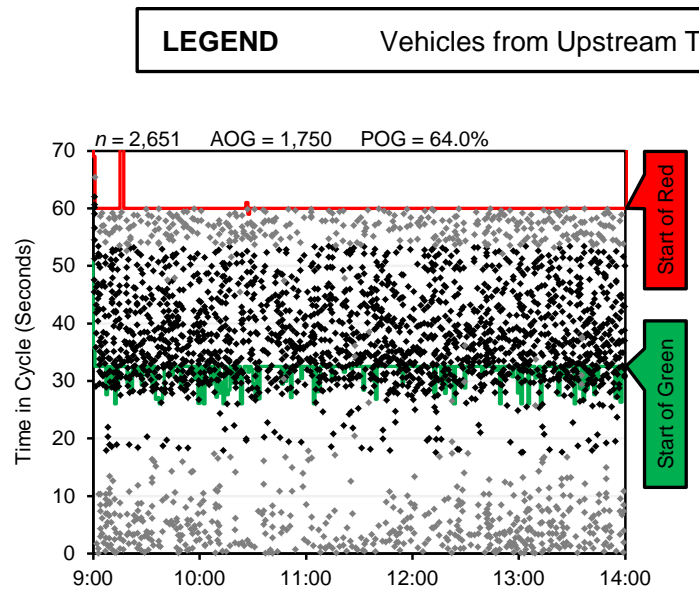

a) Northbound PCD (OL-G)

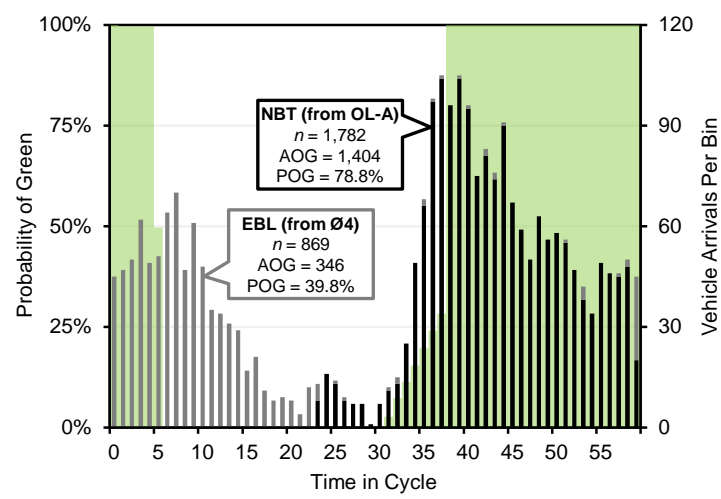

c) Northbound Flow Profile (OL-G)

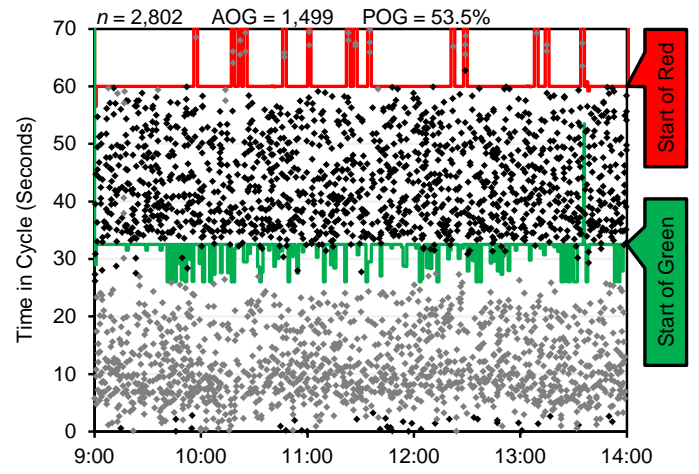

b) Southbound PCD (OL-C)

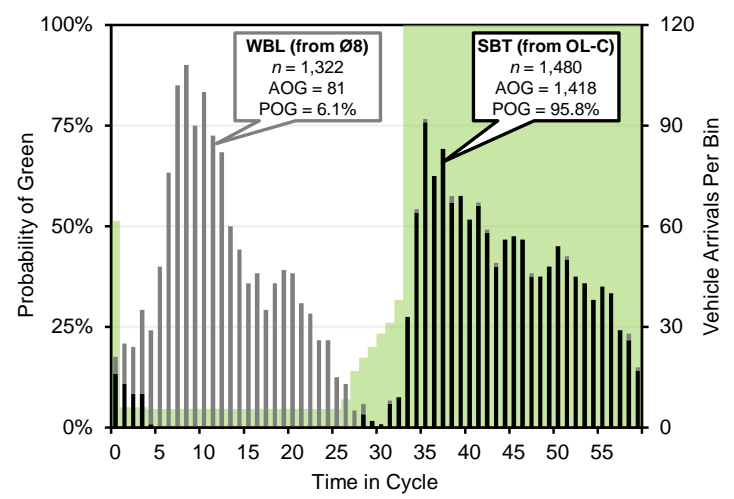

d) Southbound Flow Profile (OL-C)

Figure 2 Performance measures for base 2-phase conditions on 12/17/2013 


\begin{tabular}{|lll}
\hline LEGEND & Vehicles from Upstream Thru & Vehicles from Upstream Ramp \\
\hline
\end{tabular}

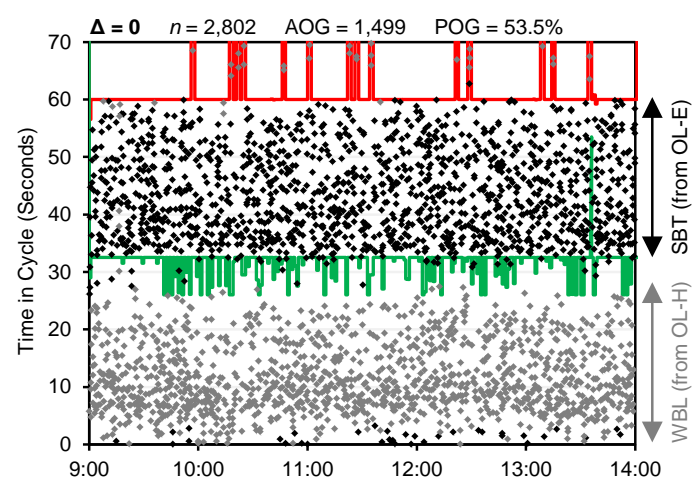

a) Delta $=+0$

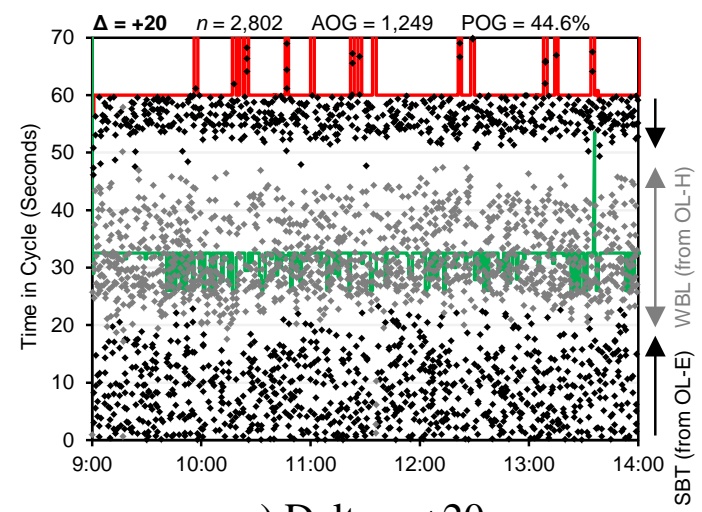

c) Delta $=+20$

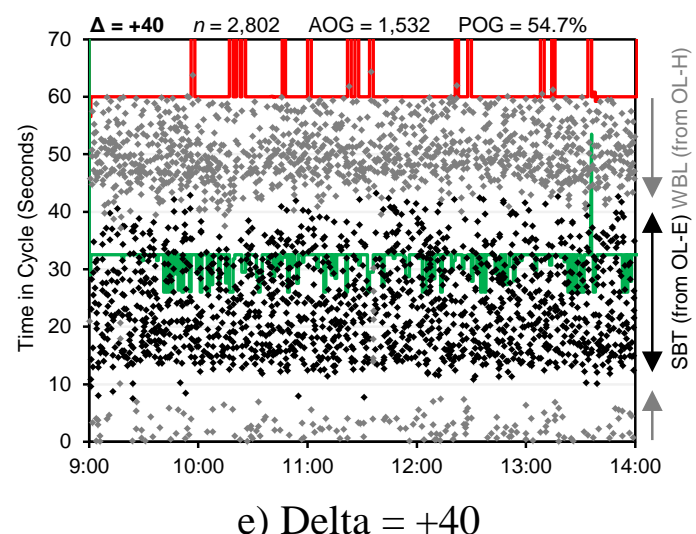

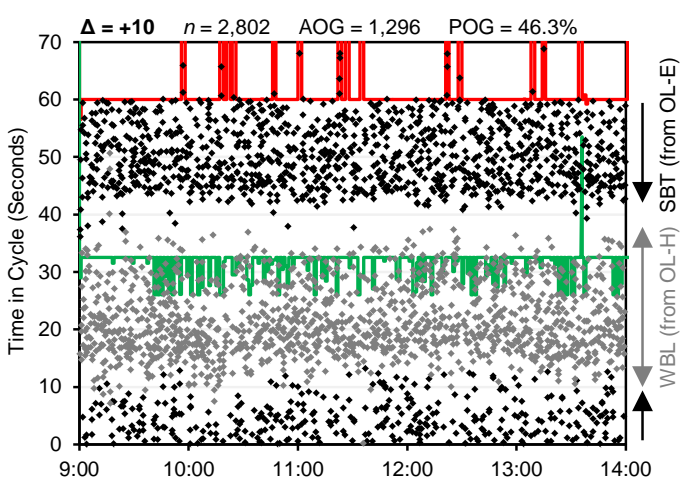

b) Delta $=+10$

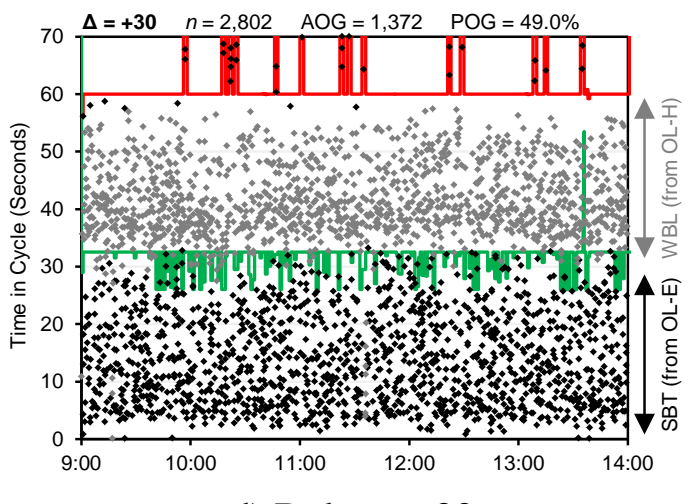

d) Delta $=+30$

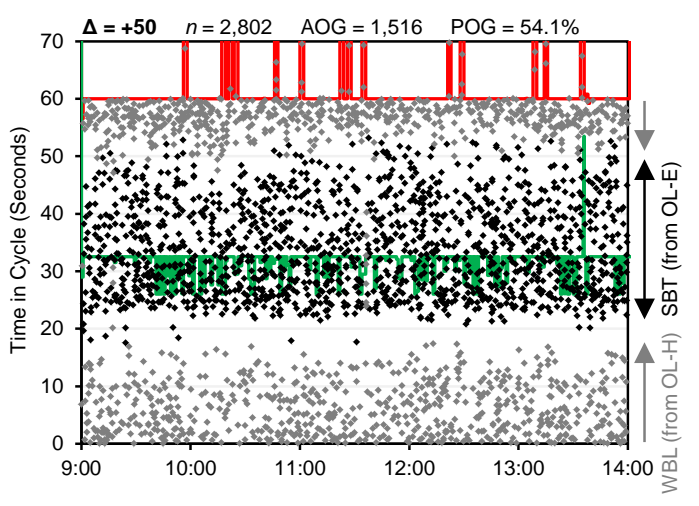

f) Delta $=+50$

Figure 3 PCDs showing the offset sweep effect on platoon arrivals (OL-C) 


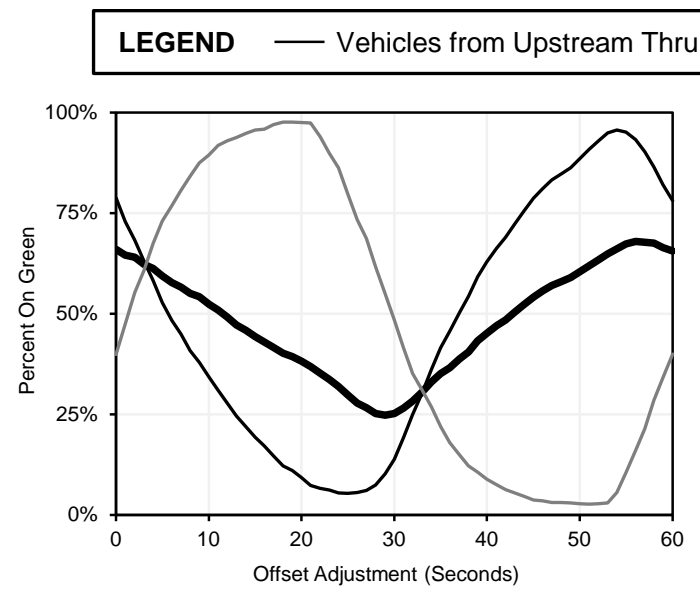

a) Northbound Percent on Green (OL-G)

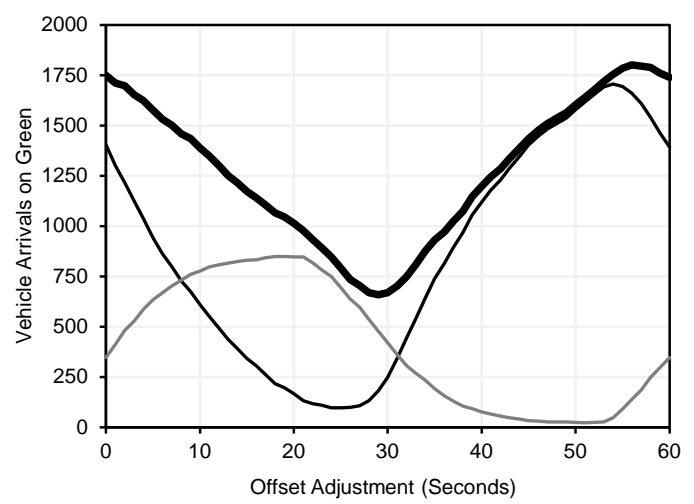

c) Northbound Arrival on Green (OL-G)

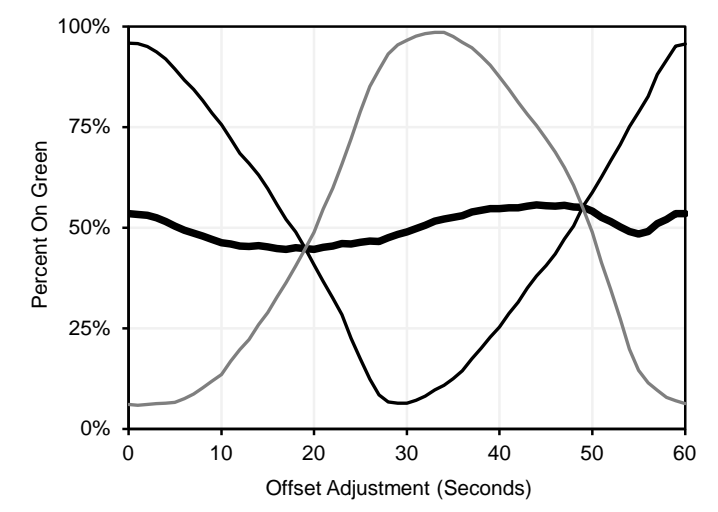

b) Southbound Percent on Green (OL-C)

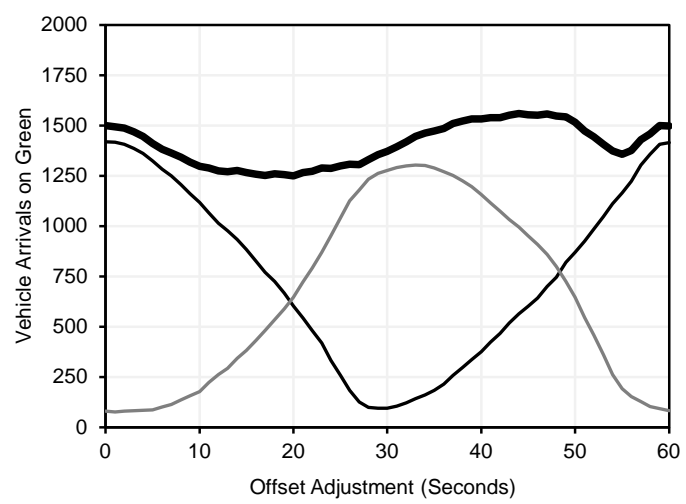

d) Southbound Arrival on Green (OL-C)

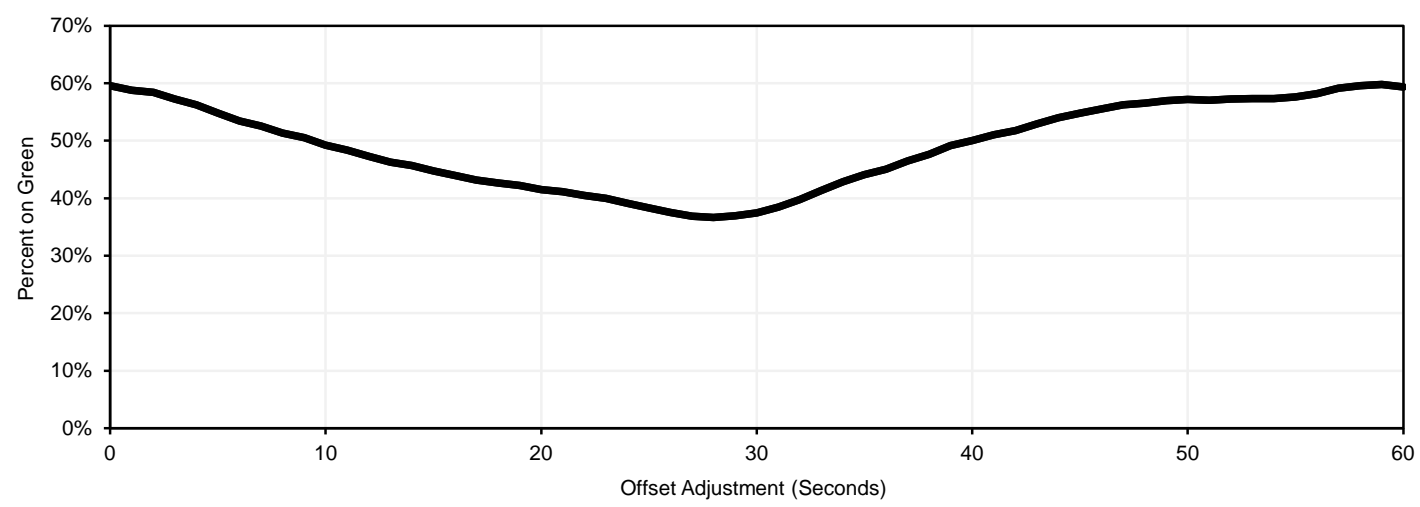

e) Total (OL-G + OL-C) Interchange Percent on Green

Figure 4 Offset sweep optimization curves 


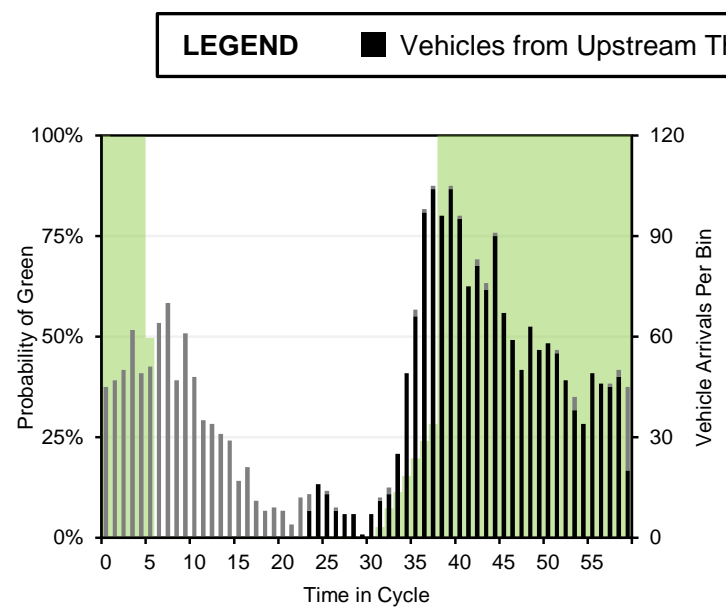

a) Northbound OL-G Before (12/17)

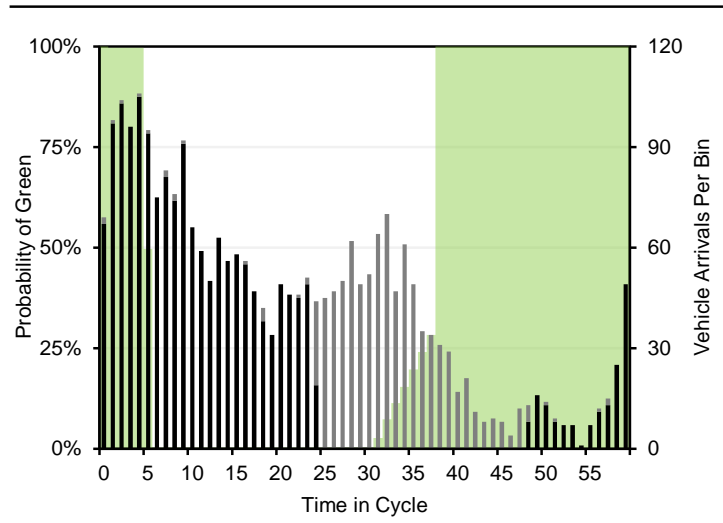

c) Northbound OL-G

Predicted (12/17)

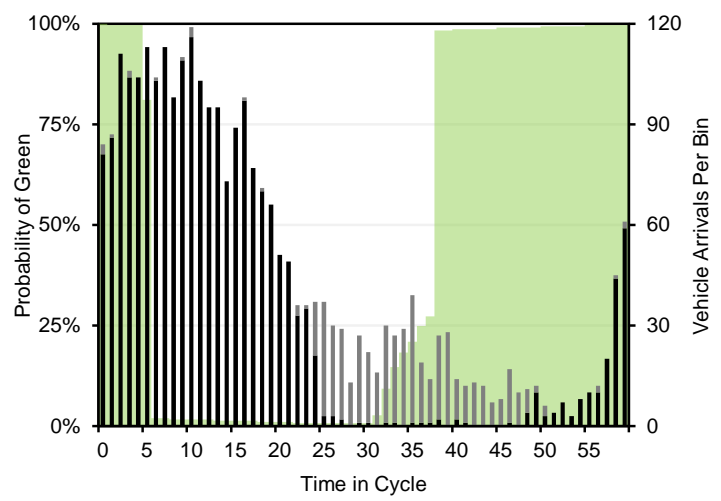

e) Northbound OL-G

After (12/18)

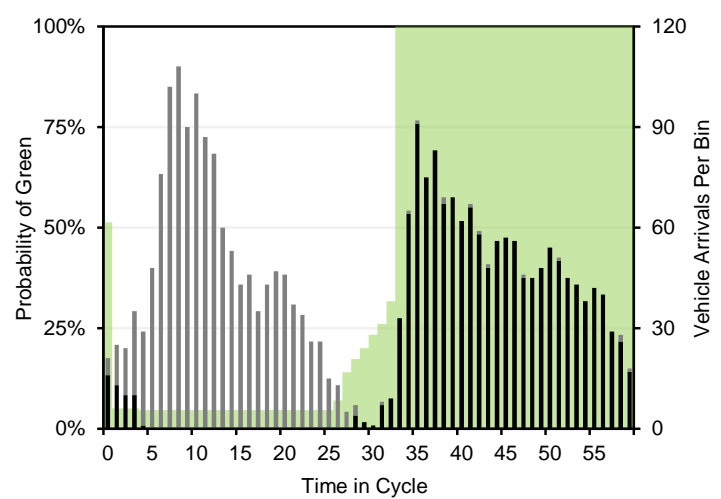

b) Southbound OL-C Before (12/17)

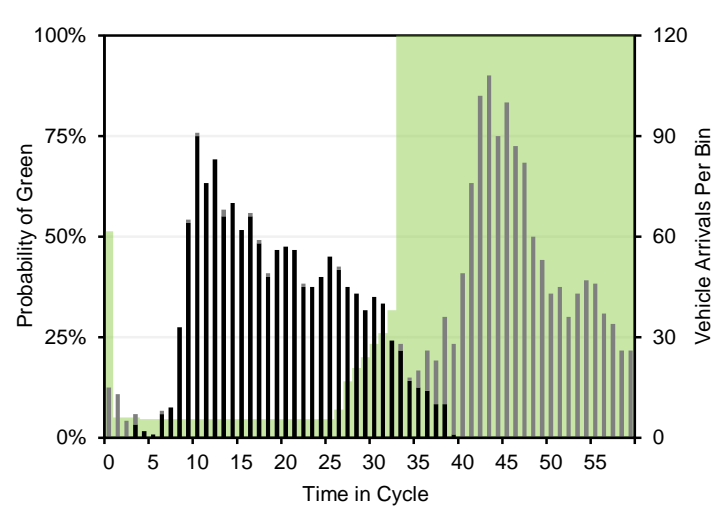

d) Southbound OL-C Predicted (12/17)

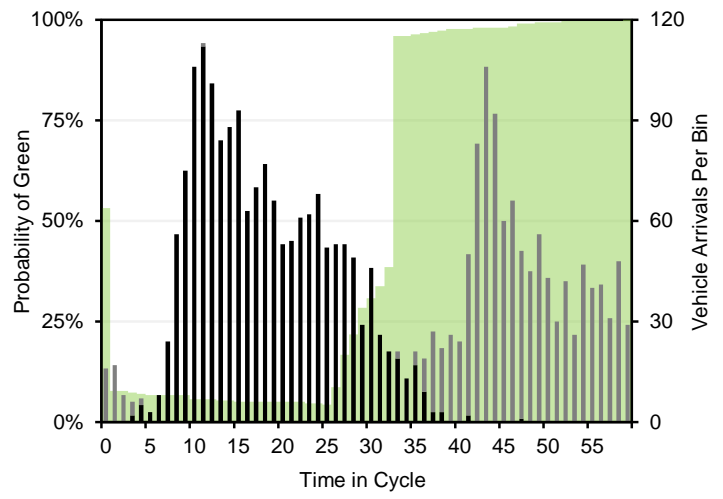

f) Southbound OL-C After (12/18)

Figure 5 Before, Predicted, and After flow profile diagrams of the offset change 


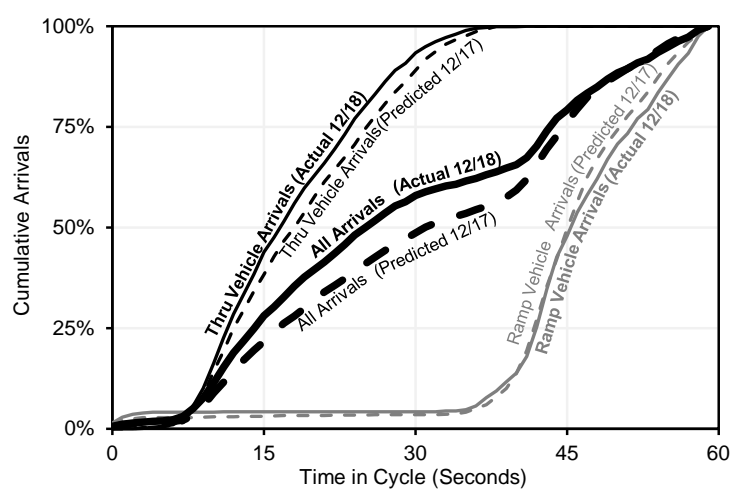

a) Southbound Cumulative Vehicle Arrival Profiles (OL-C)

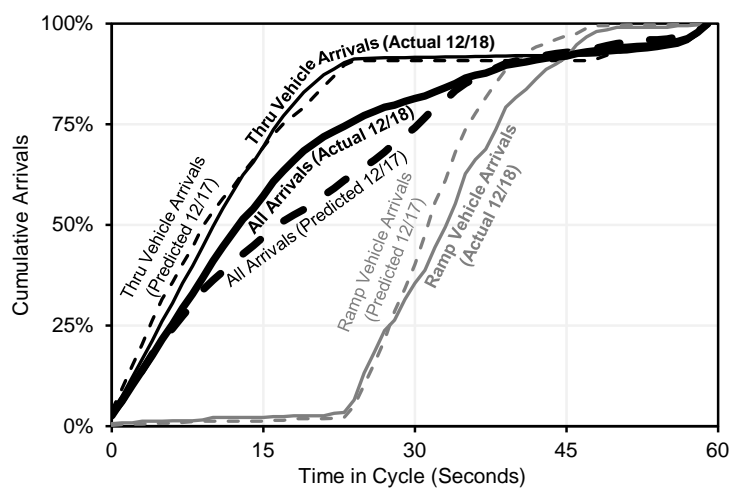

c) Northbound Cumulative Vehicle Arrivals (OL-G)

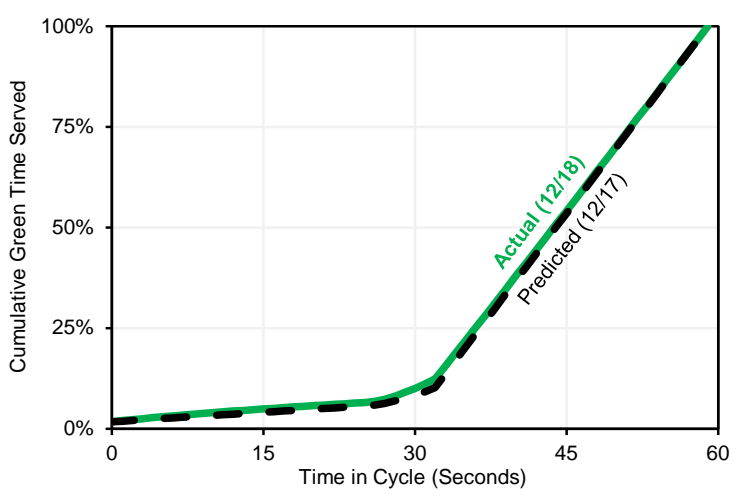

b) Southbound Cumulative Green Time (OL-C)

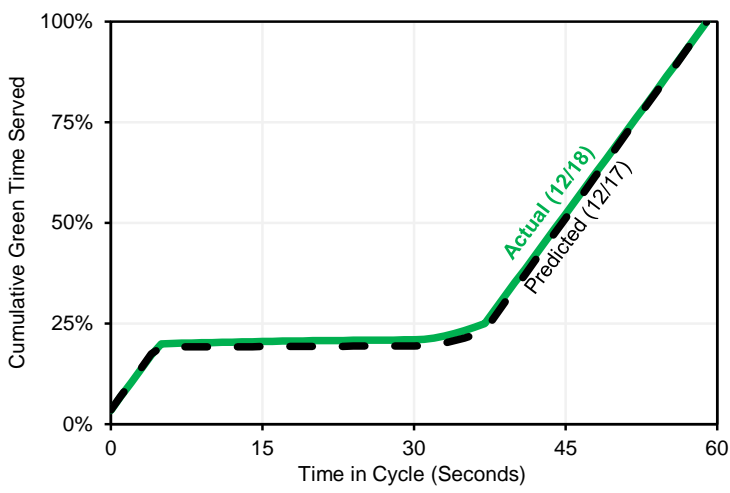

d) Northbound Cumulative Green Time (OL-G)

Figure 6 Model performance evaluation 


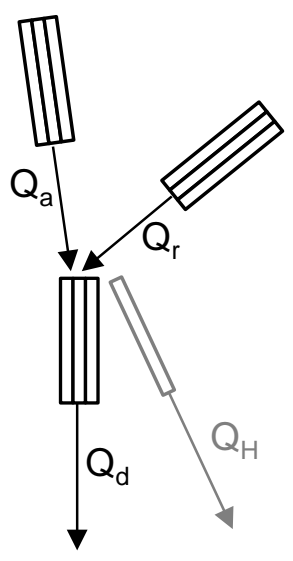

Figure 7 Flow diagram of DDI inputs and outputs 


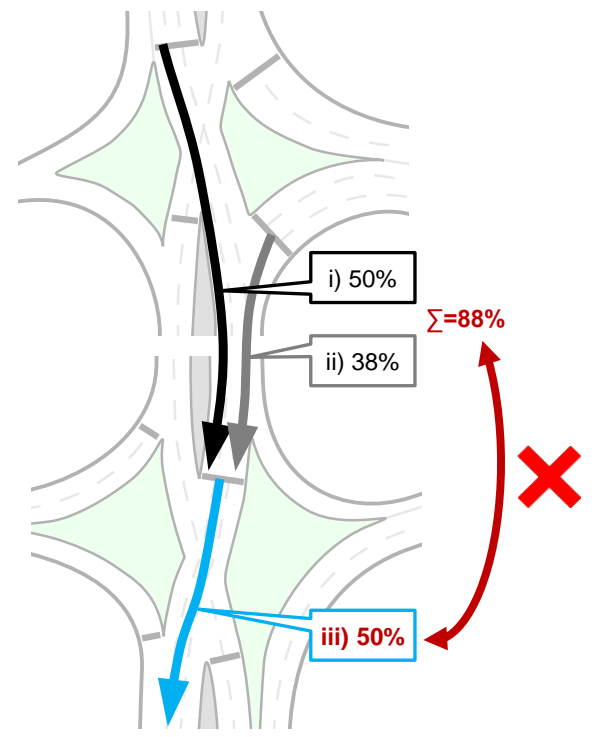

a) 2-Phase Pipe Flow Imbalance

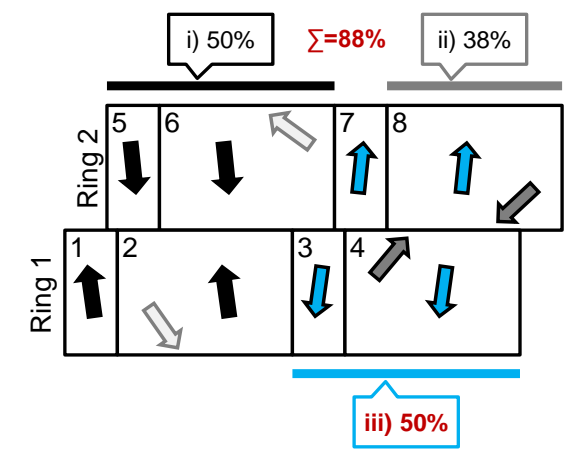

c) 2-Phase Ring Diagram $(\mathrm{CL}=60 \mathrm{~s}, \mathrm{RD}=5 \mathrm{~s})$

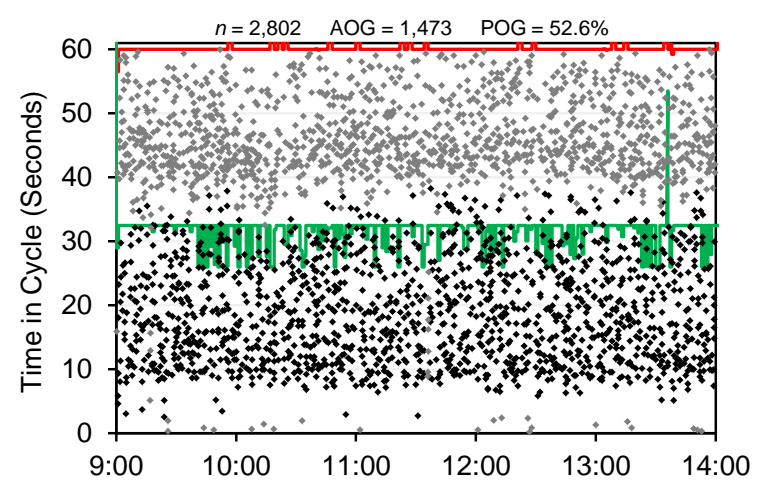

e) 2-Phase PCD

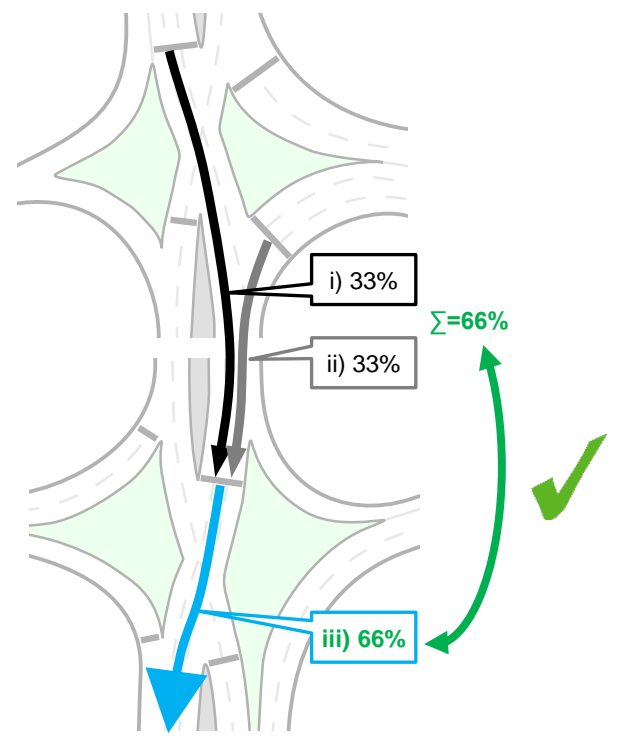

b) 3-Phase Pipe Flow Balance

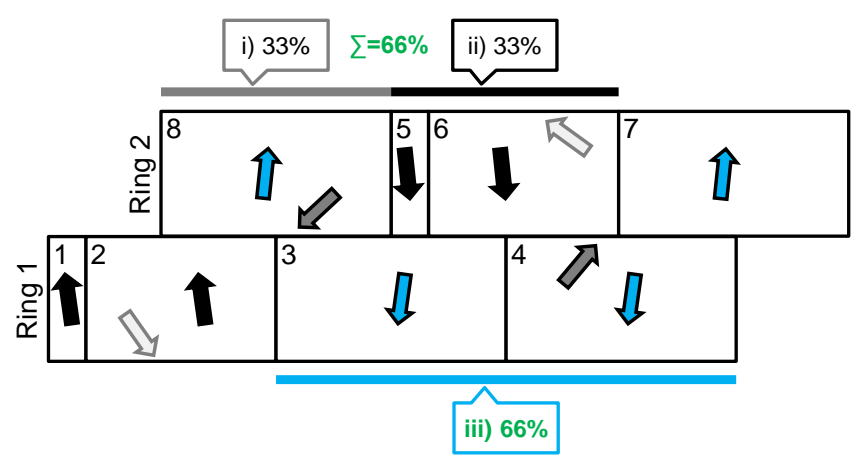

d) 3-Phase Ring Diagram $(C L=90 s, R D=45 \mathrm{~s}$ )

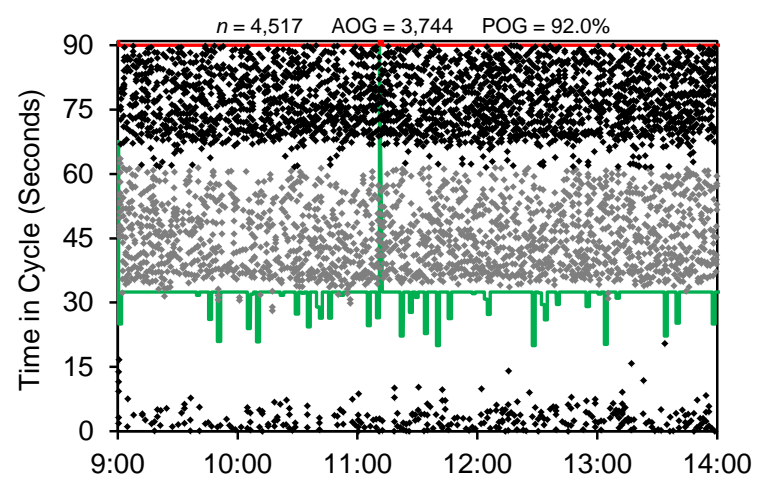

f) 3-Phase PCD

Figure 8 3-phase concept and implemenation 


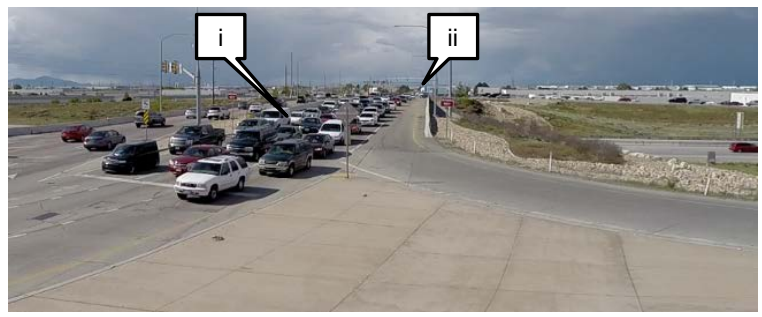

a) 2-phase w/o Holdback (Internal Queuing)

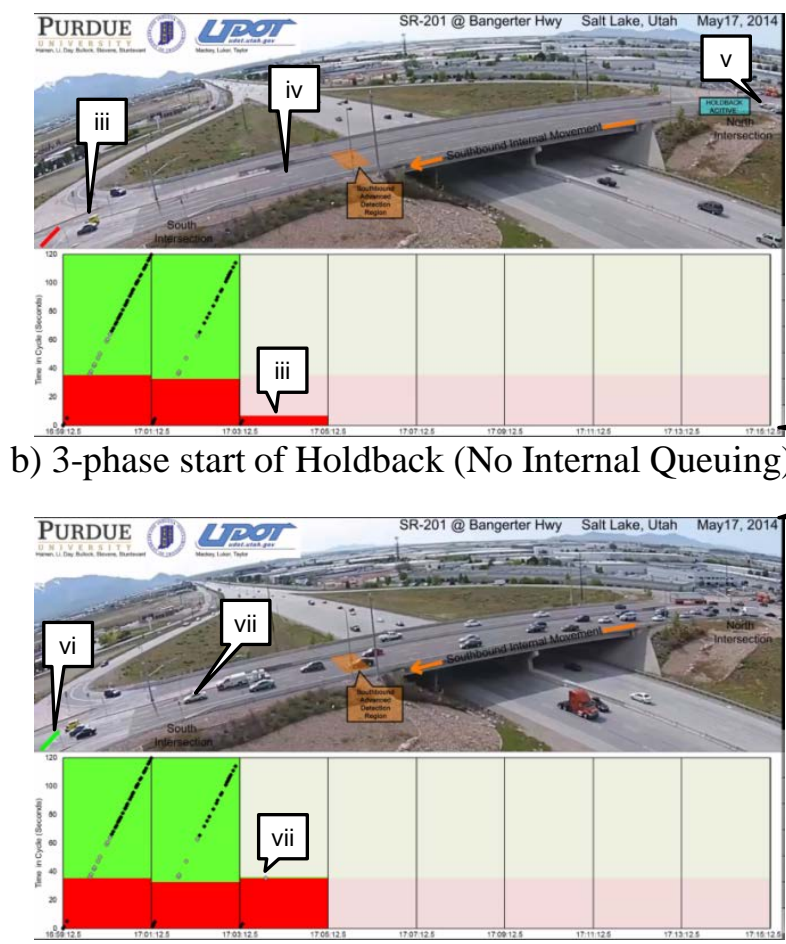

c) 3-phase clean arrival on green

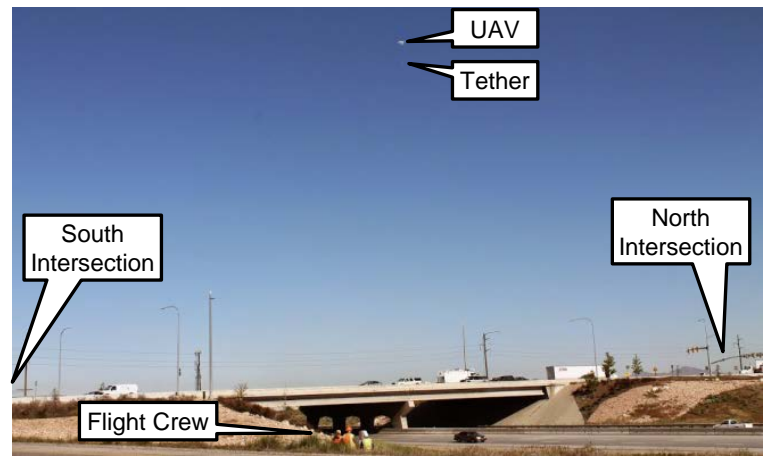

d) Tethered Unmanned Aerial Vehicle and flight crew at the interchange

Figure 9 Visual assessment with video documentation of the 3-phase implementation (http://dx.doi.org/10.4231/R7C24TC4) 